\title{
A comparative study between dynamic hip screw and intramedullary nail fixation in trochanteric fractures
}

\author{
Krishan Kumar, Anurag Chhabra*, Ashok Kumar, Sourabh Jain, Ankush Berwal
}

Department of Orthopaedics, Maharaja Agarasen Medical College, Agroha, Hisar, Haryana, India

Received: 03 May 2021

Revised: 04 June 2021

Accepted: 05 June 2021

\author{
*Correspondence: \\ Dr. Anurag Chhabra, \\ E-mail: anuragortho@mamc.edu.in
}

Copyright: (c) the author(s), publisher and licensee Medip Academy. This is an open-access article distributed under the terms of the Creative Commons Attribution Non-Commercial License, which permits unrestricted non-commercial use, distribution, and reproduction in any medium, provided the original work is properly cited.

\begin{abstract}
Background: The trochanteric fractures are one of the commonest fractures in elderly population. Incidence of these fractures is increasing due to better life expectancy, growing number of population, industrialization and the road traffic accidents. Variety of implants are available but still there is no consensus for single implant.

Methods: A prospective randomized control study was conducted on total 60 patients of intertrochanteric fractures which were randomized into 2 groups of 30 each, treated with dynamic hip screw (DHS) and proximal femoral nail (PFN). All the patients were followed up for a maximum of 6 months. Outcomes were reviewed and compared such as mode of injury, complications, functional and radiological outcomes.

Results: There was no significant difference between two groups of patients as regards to mean age and sex. The mode of injury by slip and fall was main cause. The most common type of fracture as per AO-orthopaedic trauma association (OTA) classification was 31-A2 (65\%) and 31-A3 (5\%) being the least common type. Mean surgical time of DHS group and PFN group was 125.17 minutes and 89.93 minutes respectively. Mean blood loss in DHS group and PFN group was $251.67 \mathrm{ml}$ and $158.67 \mathrm{ml}$ respectively. Mean radiological union time of fracture in DHS group and PFN group was 12.3 and 9.5weeks respectively. Mean Harris hip score at six month in DHS group and PFN group was 80.77 and 85.47 respectively.

Conclusions: We conclude that though both the implants can achieve comparable union rates but PFN are better than DHS as of better Harris hip score, shorter surgical time and less intra operative blood loss.
\end{abstract}

Keywords: Intertrochanteric, Proximal femoral nail, Dynamic hip screw, Functional and radiological outcome

\section{INTRODUCTION}

The trochanteric fractures are one of the commonest fractures in elderly population. Incidence of these fractures is increasing due to better life expectancy, growing number of population, industrialization and the road traffic accidents. In younger patients the fractures usually result from high energy trauma like road traffic accident, fall from height and accounts for only ten percent of total where as geriatric patients suffering from a minor fall can sustain fracture in this area because of weakened bone due to osteoporosis or pathological fracture and these accounts for ninety percent. ${ }^{1}$

The geriatric fractures are further associated with comorbid conditions like diabetes mellitus, hypertension, coronary artery disease, chronic renal failure, thyroid disorders and other major chronic ailments which pose a high risk for anaesthesia. This imposes a significant challenge to orthopaedic surgeon for its efficient management by early mobilization whether in elderly to reduce morbidity and mortality or in young to bring back to pain free productive life. All the circumstances 
mentioned above require using an urgent surgical solution for early rehabilitation and mobilization of the patient. ${ }^{2,3}$

Even surgical management has kept changing and evolved with development of newer concepts and implants. These implants fall into two main categories, extramedullary and intramedullary. Dynamic hip screw (DHS) most commonly used extramedullary implant is still considered the gold standard for treating intertrochanteric fractures by many. The advantages and disadvantages of the DHS have been well established in several studies done in the past. ${ }^{4}$

With the introduction of intra-medullary concept and devices, Nail in 1988 and later proximal femoral nail (PFN) in 1996 by AO/ASIF group, the intramedullary devices have gained attention and popularity globally. ${ }^{15}$

Since use of intramedullary devices in last two decades, there are several systematic reviews and meta-analysis to compare the efficacy of intramedullary devices and a conventional DHS implants but still there is no consensus on clear cut choice of implant in management of trochanteric fractures.,

The objective of this study was to compare the DHS with intramedullary nail in the treatment of trochanteric fractures in terms of union, tip apex distance (TAD), related complications and functional outcome by using Harris hip score.

\section{METHODS}

\section{Study design}

\section{Methodology}

A prospective randomized control study on 60 patients of intertrochenteric fractures was done from October 2018 to April 2020 at Maharaja Agarasen Medical College, Agroha, Hisar, Haryana, India. All the patients were subjected to routine pre-anesthetic investigations. All the patients underwent a process of randomization by chit method and divided into 2 groups (DHS and PFN group) of 30 each with the help of sealed envelopes. DHS group patients were operated with DHS implant and PFN group patients were operated with intramedullary nail (PFN). Patients were informed about the study in all respects and informed consent was obtained from each patient. Approval to perform our study was obtained from the institutional ethical committee for human research of our institution.

Statistical testing was conducted with the statistical package for the social science system (SPSS) version 20.0.

\section{Inclusion criteria}

Patients with age above 18 years, and patients with trochanteric fracture of femur not associated with any other major fracture which may impact the total outcome and rehabilitation; patients who were ambulatory before the injury; and patients with trochanteric fracture fit to undergo surgery with trauma duration up to 2 weeks were included in the study.

\section{Exclusion criteria}

Patients with pathological fractures due to metastasis, tumors except osteoporosis; open fractures; patients who are medically unfit for anaesthesia; patients with psychiatric and chronic neuromuscular disorders; trauma duration more than 2 weeks; and patients not willing to take part in study were excluded.

Initial assessment of the patients was performed in the accident and emergency centre of our institution. The injured limb was examined for deformity, wounds and neurovascular integrity. Antero-posterior, lateral radiographs of the hip were performed. Fractures were classified using AO-OTA classification. The duration of follow up was 6 months. The all cases were operated on fracture table under spinal anaesthesia, with standard approach for DHS and PFN. Five days intravenous antibiotics and appropriate analgesic were given. Hip and knee physiotherapy started on 2nd postoperative day. Partial and full weight bearing was started as early as patients' tolerance and nature of fracture. Each patient is followed up and assessed clinically and radiologically at 6 , 12,18 and 24 weeks. Range of movement at hip and knee on both sides were compared. Radiographs were taken to assess union and residual angulations at fracture site. Limb length measurement was also done. The final outcome was analyzed at 24 weeks follow up. An objective questionnaire on the basis of Harris hip score was calculated for functional outcome. Radiological assessment was done based on fracture union, varus valgus mal-alignment, complications like screw cut out, implant breakage or aseptic loosening. Depending on these criteria, results were graded and compared.

\section{RESULTS}

The average age of the study patients was 60.67 years and 65.87 years in DHS group and PFN group respectively. Sixty three percent patients were males and $36.7 \%$ patients were females. Forty percent of the patients sustained a right sided fracture. Majority of patients (91.6\%) walked without support before injury and $8.6 \%$ patients were walking with support prior to injury. Most common cause of fracture was domestic fall $(83.3 \%)$ and road traffic accident (16.6\%). Associated injuries included extraarticular fractures of distal end radius which were managed conservatively. The most common type of fracture as per AO-OTA classification was 31-A2 $(65 \%)$ and $31-\mathrm{A} 3(5 \%)$ being the least common type. Close reduction of fracture was done in all 60 patients. However 3 patients in DHS group and 4 patients of PFN group were managed by indirect closed reduction with minimal invasive reduction procedures. In post-operative period we found inguinal and proximal medial thigh hematoma/bruise caused by 
sacral post of traction table in four patients of DHS group and two patients of PFN group. The duration of hospital stay of patients in both groups was comparable but PFN group patients had slightly less duration of hospital stay. Mean surgical time of DHS group and PFN group was 125.17 minutes and 89.93 minutes respectively. Mean blood loss in DHS group and PFN group was $251.67 \mathrm{ml}$ and $158.67 \mathrm{ml}$ respectively. Mean partial weight bearing time of DHS group and PFN group was at 3.9 and 1.5 weeks respectively and full weight bearing at 10.2 and 8.8 weeks in DHS group and PFN group respectively. Mean radiological union time of fracture in DHS group and PFN group was 12.3 and 9.5 weeks respectively. Limb length shortening in DHS group was $0.90 \mathrm{~cm}$ and in PFN group was $0.60 \mathrm{~cm}$. At 24 weeks 4 patients of DHS group and 1 patient of PFN group reported with persistent pain around thigh reason. The pain is thought to be due the fact that the extramedullary implants are almost completely outside the bone, in the soft tissue, and hence interact more with soft tissue and cause pain to the patient.

Table 1: Functional mean result Harris hip scoring system.

\begin{tabular}{|c|c|c|c|c|}
\hline \multirow{2}{*}{ Parameter } & \multicolumn{4}{|c|}{ Harris hip score } \\
\hline & Excellent $>90$ & Good 80-89 & Fair 70-79 & Poor $<70$ \\
\hline DHS & 1 & 22 & 7 & 0 \\
\hline PFN & 5 & 24 & 1 & 0 \\
\hline
\end{tabular}

Table 2: Final parameters at 24 weeks follow up.

\begin{tabular}{|lllll|}
\hline Parameter & DHS & PFN & P value & Test \\
\hline Duration of surgery (minutes) & 125.17 & 89.93 & $0.001(\mathrm{~S})$ & Unpaired t \\
\hline Blood loss (ML) & 251.67 & 158.67 & $0.001(\mathrm{~S})$ & Unpaired t \\
\hline Total hospital stay (days) & 21.07 & 19.90 & 0.36 & Unpaired t \\
\hline Partial weight bearing (weeks) & 3.9 & 1.5 & $0.001(\mathrm{~S})$ & Unpaired t \\
\hline Full weight bearing (weeks) & 10.2 & 8.8 & $0.001(\mathrm{~S})$ & Unpaired t \\
\hline Shortening (cm) & 1.01 & 0.57 & $0.001(\mathrm{~S})$ & Unpaired t \\
\hline Shortening $>\mathbf{1 . 5} \mathbf{~ c m}$ & 0 & 3 & $0.01(\mathrm{~S})$ & Chi square \\
\hline Tip apex distance $(\mathbf{c m})$ & 1.9000 & 1.3697 & $0.001(\mathrm{~S})$ & Unpaired t \\
\hline Nonunion & 0 & 0 & & \\
\hline Cut out & 0 & 0 & & \\
\hline Union in weeks & 12.3 & 9.5 & $0.001(\mathrm{~S})$ & Unpaired t \\
\hline Harris hip score & $80.77 \pm 9.641$ & $85.47 \pm 3.758$ & $0.001(\mathrm{~S})$ & Unpaired t \\
\hline Functional result excellent & 1 & 5 & $0.01(\mathrm{~S})$ & Chi square \\
\hline
\end{tabular}

Table 3: Postoperative complications.

\begin{tabular}{|lll|}
\hline Post operative complications & DHS & PFN \\
\hline Condition of wound (soakage) & 4 & 1 \\
\hline Pain at fracture site and swelling & 2 & 1 \\
\hline Fever & 0 & 0 \\
\hline Deep vein thrombosis & 0 & 0 \\
\hline Superficial infection & 2 & 0 \\
\hline Discharge sinus & 0 & 0 \\
\hline Bed sores & 3 & 0 \\
\hline Neurovascular complications & 0 & 0 \\
\hline $\begin{array}{l}\text { Pressure sore/bruise by sacral post } \\
\text { mark }\end{array}$ & 4 & 2 \\
\hline Knee stiffness & 3 & 1 \\
\hline Screw cut out & 0 & 0 \\
\hline $\begin{array}{l}\text { Screw migration, Z effect, reverse } \\
\text { Z effect }\end{array}$ & 0 & 0 \\
\hline
\end{tabular}

Final functional results were assessed by using Harris hip score at six months. Five patients $(16.66 \%)$ had excellent result in PFN group and one patient (3.3\%) had excellent result in DHS group. Good result in DHS group and PFN group were $73.3 \%$ and $79.9 \%$ respectively. Fair result in DHS and PFN groups were23.3\% and 3.3\% respectively. None of groups had poor results.

\section{Postoperative complications}

Postoperative complications are as mentioned in Table 3. Superficial wound infection were managed with intravenous antibiotics for 4-5 days followed by oral antibiotics. We observed pressure mark/bruise on medial aspect of thigh and inguinal region caused by sacral post of traction table in four patients of DHS group and two patients of PFN group, which resolved with time.

Mean Harris hip score at six month in DHS group and PFN group was 80.77 and 85.47 respectively. At final follow up at 24 weeks, DHS group presented with no patient of poor functional outcome, 7 with fair, 22 with good and 1 patient with excellent outcome. PFN group had no patients with poor outcome, 1 had fair, 24 had good and 5 patients had excellent outcome. In DHS group, one patient was fixed intra-operatively in varus angulation of 5 degree which did not affect the final functional outcome. No patient had 
screw cut-out, $\mathrm{z}$ or reverse $\mathrm{z}$-effect, implant failure and revision surgery in follow-up.

Pre/post-operative and follow up x-rays examples in PFN group are given in Figure 1-3 and in DHS group are given in Figure 4-6.

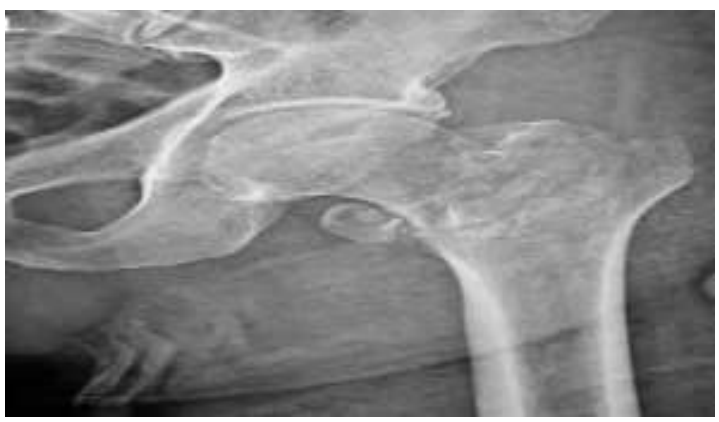

Figure 1: Preoperative.

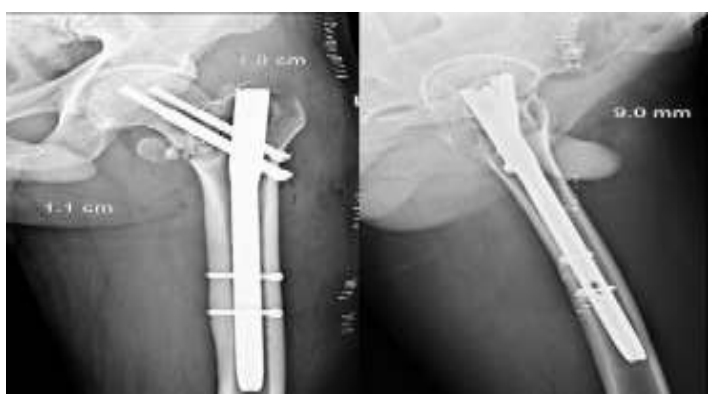

Figure 2: Postoperative.

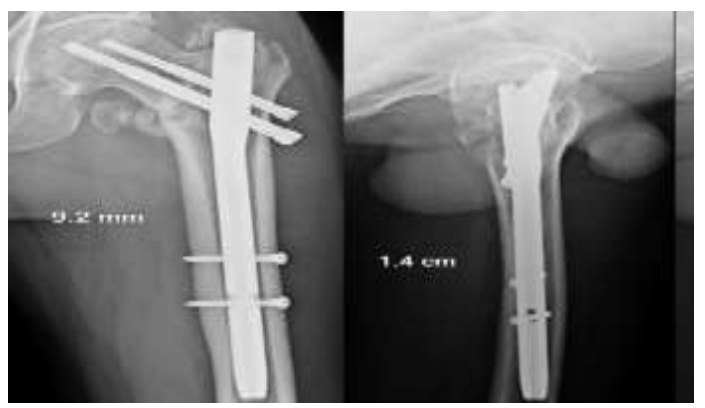

Figure 3: At 24 weeks.

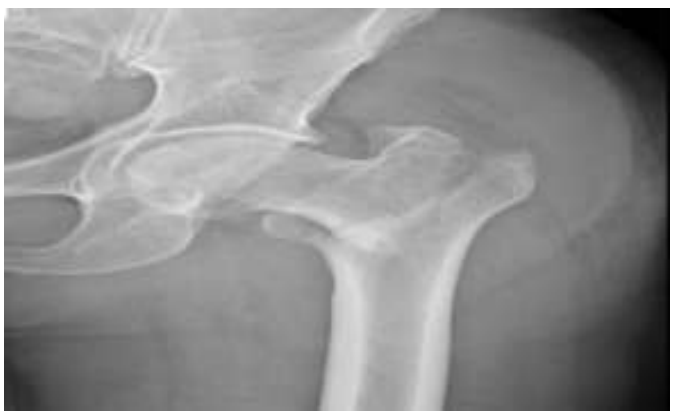

Figure 4: Preoperative.

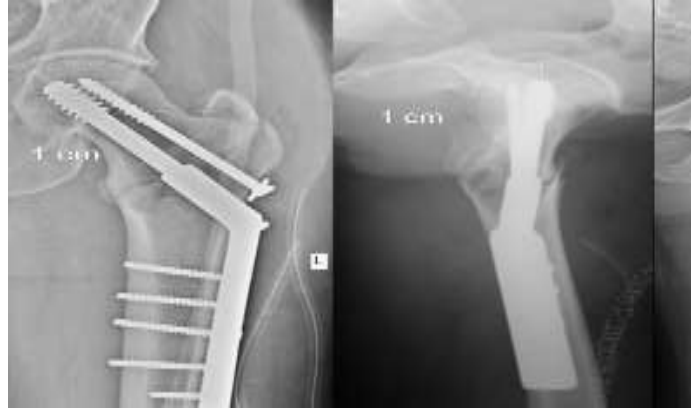

Figure 5: Postoperative.

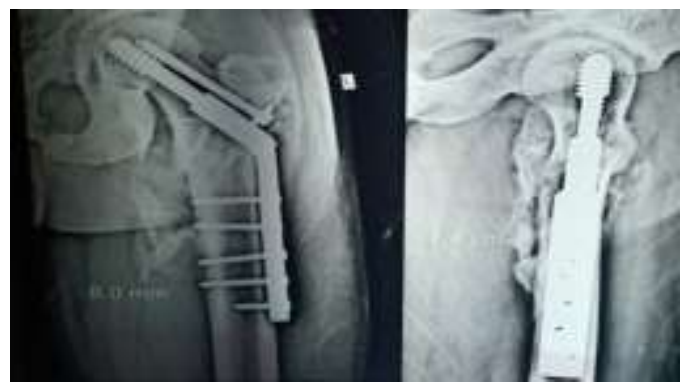

Figure 6: At 24 weeks.

\section{DISCUSSION}

Our series consisted of 30 patients in each group operated with DHS and PFN, the mean age of DHS and PFN group had no statistically difference which is comparable to Sharma et al whereas the mean age is higher in studies by Gupta et al and Mathew et al., ${ }^{2,6,13}$ The male and female ratio in our study is comparable but contrary to our study Gupta et al, Gill et al and Sharma et al reported female predominance in both groups and Mathew et al reported male predominance. ${ }^{6,10,13}$ In our study fractures were more in left side in both groups. Contrary to our study Gill et al and Kumar et al observed right side preponderance in their study. ${ }^{10,11}$ In our study 27 patients of DHS group and 28 patients of PFN group walked without support and 3 patients of DHS group and 2 patients of PFN group walked with support before injury. Gill et al reported similar data. ${ }^{10}$ The mode of injury in majority of patients in both group was by slip and fall a few sustained injury by RTA, 2 patients in DHS group and 1 patient in PFN group had associated injury of distal end radius which similar observed in studies of Gill et al, Neikar et al and Kameshwar et al. ${ }^{10,12,14}$ Co-morbidities have been reported by all researchers in geriatric age group and which is also expected. In our study 17 patients in DHS group and 20 patients in PFN group presented with co morbidities like diabetes, hypertension, epilepsy, hypothyroidism, chronic obstructive pulmonary disease (COPD), hypertension, bladder stone, calcified fibroid uterus and unhealthy life style habits like alcoholism and smoking. The most common type of fracture as per AO-OTA classification in our study was $31-\mathrm{A} 2(65 \%)$ and $31-\mathrm{A} 3(5 \%)$ being the least common type, similar domination of 31-A2 fracture was observed in other studies like Mathew et al which had 
$68.8 \%$, Myderrizi et al had $58.7 \% .^{2,9}$ Closed reduction was done in all patients in both groups as it allows minimal soft tissue handling, preservation of fracture hematoma. However indirect closed reduction was done with minimal invasive reduction technique (with help of Steinmen pin) in three patients of DHS group and four patients of PFN group. In our study the mean blood loss in DHS group was higher than PFN group. In comparison to our study, Mathew et al, Walia et al and Gill et al reported more blood loss and Myderrizi et al reported less blood loss in both the groups..$^{2,3,9,10}$ In our study the mean surgical time was less in PFN group as compared to DHS group whereas Walia et al, Myderrizi et al and Gill et al reported overall less surgical time in both group as compared to our study. $3,9,10$ The tip apex distance less than $2.5 \mathrm{~cm}$ is used as radiological assessment tool for proper placement of screw position to prevent screw cut outs, $\mathrm{Z}$ effect and reverse $\mathrm{Z}$ effect. In our study tip apex distance was found more than $2.5 \mathrm{~cm}$ in three patients of DHS group and one patient of PFN group. It was less than $2.5 \mathrm{~cm}$ in rest of the patients. This is the most likely reason of no screw cut out, no $\mathrm{Z}$ or reverse $Z$ effect was seen in any group. There was no significant difference in mean hospital stay but mean hospital stay in PFN group was less as compared to DHS group. However the overall hospital stay in DHS group was more than PFN group in all studies except in Kumar et al. ${ }^{11}$ In our study the radiological union time was less in PFN group compared to DHS group, the similar observations were seen in union time of our DHS group is comparable to Walia et al and Gill et al.,10 Mean shortening of limb length discrepancy in our study was found less in PFN group then DHS group. Sharma et al reported one case each of loss of reduction, technical error, implant failure, second surgery and two case of prolonged drainage in DHS group and PFN group. ${ }^{13}$ We had no such complication except of mild soakage in postoperative wounds. No study discussed about complication of traction table, we observed 4 patients in DHS group and 2 patients in PFN group had pressure sore/bruise by sacral post. In our study there was statically significant difference of Harris hip score at 6 weeks on first follow up i.e. higher in PFN group. Overall PFN group had more mean Harris hip score in all follow ups but the difference in mean scores at later follow ups decreased gradually till final follow up done at 24 weeks. As a result of weight sharing property, shorter lever arm and being an intra-medullary implant (PFN group) patients ambulated early and had higher Harris hip scores on initial follow ups, however on later follow-up mean score difference decreased between the groups. The mean Harris hip score at 24 weeks in studies by Faisal et al and Myderrizi et al were comparable to our study. ${ }^{7,9}$

\section{CONCLUSION}

Final result of our study was assessed by Harris hip score, functional outcome, union time, intra operative blood loss and surgical duration. Our study had short term follow up, a long term follow up and larger series is required for better understanding, Hence we conclude that though both the implants can achieve comparable union rates in operated patients of intertrochanteric fracture but intramedullary implants (PFN) are better than DHS due to the fact that it allows for early ambulation, better Harris hip score, early return of pre-injury activity, lesser shortening, shorter surgical time and less intra operative blood loss.

Funding: No funding sources

Conflict of interest: None declared

Ethical approval: The study was approved by the institutional ethics committee

\section{REFERENCES}

1. Saarenpaa I, Heikkinen T, Ristiniemi J, Hyvönen P. Functional comparison of the dynamic hip screw and the Gamma locking nail in trochanteric hip fractures: a matched-pair study of 268 patients. Int Orthop. 2009;33:255-60.

2. Mathew A. The use of an Intramedullary Nail vs. Dynamic Hip Screw in the treatment of Intertrochantric fractures; a case cohort study. Kerala J Orthop. 2012;25:6-13.

3. Walia JPS, Tailor H, Mann HS, Gupta AS, Rehncy JS, Singh S. A comparative study of 30 cases of trochanteric fracture femur treated with dynamic hip screw and proximal femoral nail. $\mathrm{Pb} \mathrm{J}$ Orthop. 2013;16:6-10.

4. Zhang K, Zhang S, Yang J, Dong W, Wang S, Cheng $\mathrm{Y}$ et al. Proximal Femoral Nail vs. Dynamic Hip Screw in Treatment of Intertrochanteric Fractures: A Meta-Analysis. Med Sci Monit. 2014;20:1628-33.

5. Kumar V, Singh A, Bharti A, Dalmia D, Ali S. A Comparison of Intramedullary and Extramedullary Fixation Devices in Unstable Trochanteric Fractures. Int J of Biomed Adv Res. 2014;5(7):335-9.

6. Gupta SKV, Valisetti VS. Comparative study between dynamic hip screw vsproximal femoral nailing in inter-trochanteric fractures of the femur in adults. Int J Orthop. 2015;1:7-11.

7. Faisal M, Nistane P. Proximal Femoral Nailing vs. Dynamic Hip Screw in unstable Intertrochanteric Fracture of Femur - A comparative analysis. Int J of Biomed Res. 2016;7:489-92.

8. Yadav S, Srivastava DC, Shukla M. Comparative evaluation of dynamic hip screw and proximal femoral nail for fracture of intertrochanteric femur. Int J Res Orthop. 2016;2:286-90.

9. Myderrizi N. Proximal femoral nailing is better choice in treatment of intertrochanteric fracture in elderly people. Int Surg J. 2016;3:781-5.

10. Gill SPS, Mittal A, Raj M, Singh P, Kumar S, Kumar D. Dynamic hip screw with locked plate versus Proximal Femoral Nail for the management of intertrochanteric fracture: A comparative study. Int $\mathrm{J}$ Orthop. 2017;3:173-80.

11. Kumar A, Jain A, Agrawal A, Sah M, Bansal A, Desai S. Outcome of proximal femur fracture treated with long proximal femoral nail and dynamic hip screw. Int J Orthop. 2017;3:600-6. 
12. Neikar S, Sajjan NY, Telkar NB, Nasequddin S. Clinical research on dynamic hip screw and proximal femoral nail in the treatment of intertrochanteric fractures. J Evid Based Med Healthc. 2017;4(90):5350-4.

13. Sharma A, Sethi A, Sharma S. Treatment of stable intertrochanteric fractures of the femur with proximal femoral nail versus dynamic hip screw: a comparative study. Revistabrasileira de ortopedia. 2018;53(4):477-81.

14. Kameshwar I, Rao SV, Haranadh K, Damera Y, Ashwani N. PFN-Future in Intertrochanteric Fracture Treatment. Galore Int J Health Sci Res. 2018;3(4):915.
15. Müller ME, Nazarian S, Koch P, Schatzker J. The comprehensive classification of fractures of long bones. Springer Berlin. 1990;8:116-27.

16. Meesala VB, Padala A, Pathri S. DHS Versus PFN in Stabilization of Intertrochanteric Fractures-A Comparative Study. J Evid Based Med Healthc. 2018;5(46):3183-6.

Cite this article as: Kumar K, Chhabra A, Kumar A, Jain S, Berwal A. A comparative study between dynamic hip screw and intramedullary nail fixation in trochanteric fractures. Int J Res Orthop 2021;7:794-9. 